\title{
DEVELOPMENT AND APPLICATION OF LANDFILL PRETREATMENT TECHNOLOGIES FOR ASIA
}

\author{
B. F. A. Basnayake \\ C. Visvanathan ${ }^{2}$ \\ ${ }^{\prime}$ University of Peradeniya, Sri Lanka \\ 'Asian Institute of Technology, Thailand.
}

\begin{abstract}
Most of the local authorities in Sri Lanka and in most parts of Asia has resorted to open dumping or controlled dumping of wastes wherein lands are becoming a limited resource. Landfill pretreatment technologies prolong the life of landfills and thus, the research focused on improvements to existing and new inventions. Many composting methods: windrows, static piles of different methods and aerobic reactors were tested and experimented. In taking advantage of energy extractions, anaerobic digesters with up and downward flow was compared. Furthermore new designs of horizontal hydrolytic/acidogenic reactor and a hybrid system were developed and tested. In both biological transformations, process conditions were optimized kinetically. Small windrows and static piles did not satisfy WHO standards. However, mixing ten-day old wastes with raw wastes has stabilized the decomposing waste rapidly. Mass and volume reductions were $56 \%$ and $67 \%$, respectively. Even in large scale applications, windrows and static piles were too costly. In comparison, Inclined Step Grate (ISG) performed best. It can also be used for maturing and aerating remaining fibres from anaerobic digestion. The fibre removals from the first stage vertical anaerobic digesters were posing numerous problems, including prolonged mass retention times (MRT). In these reactors, it was deduced that downward movement of elute (leachate) was better than up flow and that the horizontal reactor after many modifications proved to be versatile. The reactor was optimized by following the kinetic analysis that seven days were required to stabilize the reactor and every three days feeding gave 2.6 times the concentration of TDS compared to daily feeding. It reached equilibrium in less than two weeks and it was operated continuously. The hybrid system being developed at Asian Institute of Technology (AIT) seems promising with specific methane yields of 140.35 and $62.55 \mathrm{~L} \mathrm{CH}_{4} / \mathrm{kg}$ VS generated for loading rate 1 and $2 \mathrm{kgVS} / \mathrm{m}^{3}$, respectively.
\end{abstract}

\section{KEYWORDS}

Landfill pretreatment; Composting, Anaerobic digestion, Kinetics.

\section{INTRODUCTION}

Dumping of solid wastes is the major problem faced by many local authorities in South Asia. There are advanced technologies that could be applied to solve this growing problem of urban pollution. However, these technologies may be applicable with modifications and thus require scientific evaluation to sustain systems in tropical climates. In addition, the technologies should be simple and cost effective. The adaptation and development of technologies should 
consider resources that are limiting like land, particularly in small countries like Sri Lanka and such resources should be protected and life of landfills prolonged. Landfill pretreatment is one of the methods of extending the physical life of landfills, which is the core of any integrated system. In fact, municipal solid wastes (MSW) are used as a resource for illegal encroachment of wetlands, low lying lands, lagoons and river banks. It has become a political issue in some of the countries.

The lacking of 'political will' is somewhat related to uncertainties in scientific and technological advances and know-how. The other aspects are gaps in knowledge, lackadaisical approaches to the use of technologies, unaware of the real dangers to health and environment and conflicts inflicted in democratic rule and governance. Then, it is apparent that a sound 'knowledge base' is required to overcome these shortcomings. Thus the project "Sustainable Solid Waste Landfill Management in Asia" was formulated and the research focused on technologies that could move away from controlled dumpsites to sustainable landfills. Although non-biodegradable materials pose considerable problems and obstacles for establishing sustainable landfills, an effective $3 \mathrm{R}$ programs could resolve and overcome most of them. Whereas, biodegradable waste materials are one of the major causes of land, water and atmospheric pollution. For example, the EU directives are curtailing organic wastes ending up in landfills. Thus, similar policies and strategies are essential for sustaining landfills in the Asian context. The option of landfill pre-treatment technologies has also created ambiguity among many of the stakeholders, including the scientists, engineers, sociologist and economist, let alone the politicians.

The most debated question is whether to promote composting or anaerobic digestion as the best technological option for tropical climates. In fact both systems, more so of anaerobic digestion have failed. However, few successful systems exist, but in most cases, large financial supports have been given to maintain the systems. Thus, the goals of the project, reflecting in this paper, was to develop as many pre-treatment options so that integrated systems could be developed for any location in Asia. In fact, both anaerobic followed by aerobic composting would be the best combination of pre-treatment technologies to maximize the utility of the waste resources. Therefore, small to large composting systems as well as single and two-stage reactors were developed and thus reported in this paper.

\section{MATERIALS AND METHODS}

The research studies were conducted in the University of Peradeniya, Sri Lanka and Asian Institute of Technology (AIT), Bangkok, Thailand. In both of the locations, waste composition and particle size distribution studies were carried out. Bulk densities, before and after decomposition were obtained. Especially waste compositions were determined, each time a new experiment or trial was undertaken. Not only these physical properties but also energy contents and leaching column studies enabled to determine accurately mass and energy balances.

\subsection{Aerobic systems}

Number of aerobic composting systems was evaluated, namely; small to large windrow systems to conventional and inventive methods of static piles, inverted forced aeration and completely enclosed Inclined Step Grate (ISG) unit [1]. Some of the methods are illustrated below in Figures 1 and 2. The parameters that were used in the performance evaluations were: composition of wastes, volatile solid (VS) content at the beginning and throughout the decomposition process, temperature and moisture contents, bulk density variations before and after the experiment. The quality of compost was determined with bioassays. 


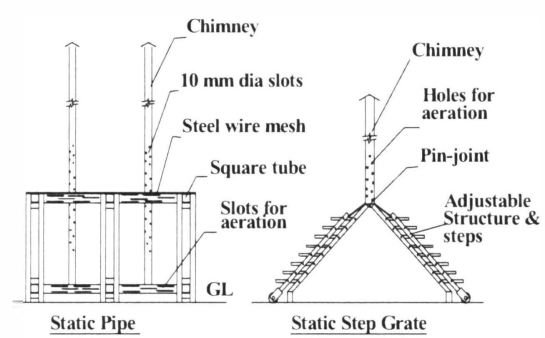

Figure 1. Static Pipe (SP) and Static Step Grate $(S G)$.

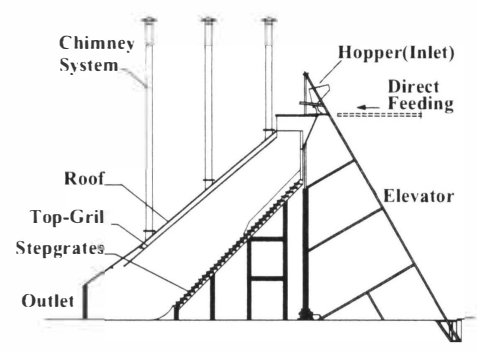

Figure 2. Inclined Step Grate system (ISG).

\subsection{Anaerobic systems}

The anaerobic systems were developed based on phase separations of two-stage reactors. In addition, single stage reactors were evaluated to assess the advantages. Number of permutations and combinations were tried to assess the best including the direction of flow (up or down), reactor orientation (vertical and horizontal) and inclined and feeding regimes (see Figure 3). The parameters that were used to determine the performances of reactors were the following: Total solids (TS), Total suspended solids (TSS), Volatile solids (VS), Volatile suspended solids (VSS), Total dissolved solids (TDS), BOD, COD, pH and temperature. The systems were analyzed based on microbial growth kinetics as described in the paper of [2].

\section{RESULTS AND DISCUSSION}

\subsection{Waste composition and energy contents}

The biodegradable component of wastes found in most parts of Southern Asia is very high. It was found that the particle sizes of the biodegradable passing though $50 \mathrm{~mm}$ sieve were $50 \%$ of the wastes in Sri Lanka and $60 \%$ of the wastes were less than $75 \mathrm{~mm}$ in Bangkok wastes. Notably, prior separation of the smaller particles could lead to smaller quantity to be size reduced [3] before pre-treating the wastes. The biodegradable wastes have an average calorific value of $17025 \mathrm{~kJ} / \mathrm{kg}$ on dry basis [4]. 


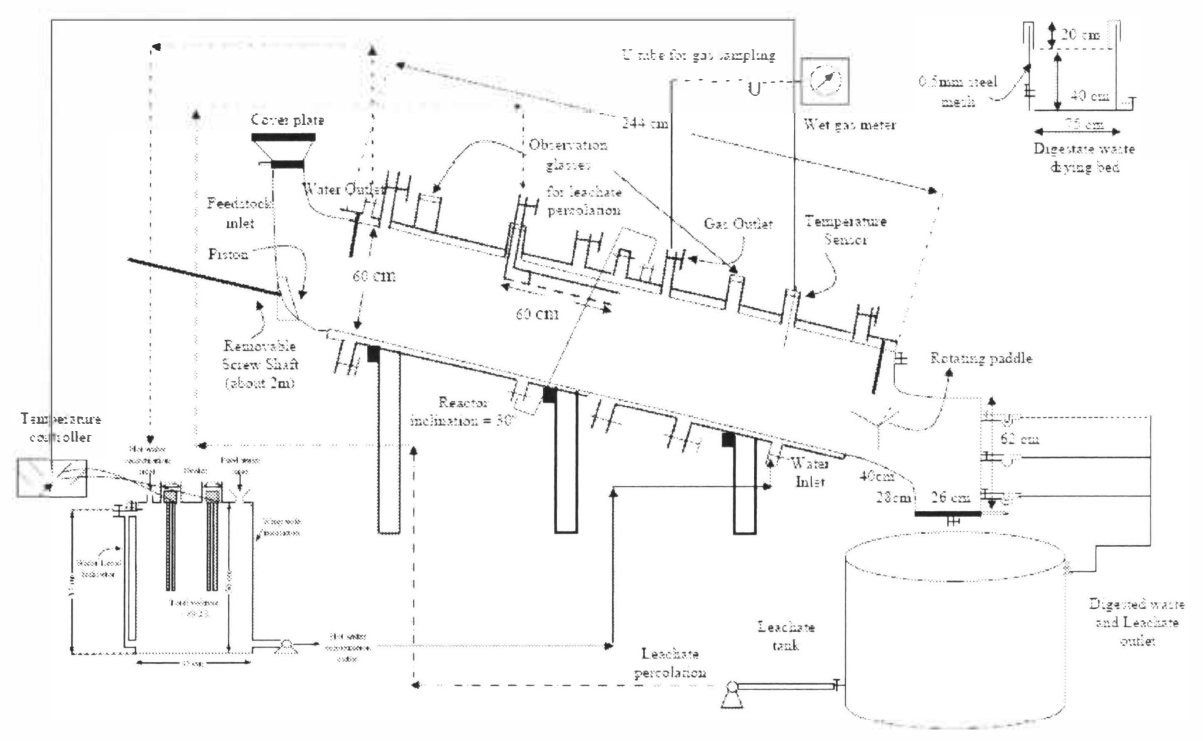

Figure 3. Inclined (hybrid) anaerobic digester.

\subsection{Aerobic systems}

\subsubsection{Windrow and static piles}

In both methods there were significant temperature gradients between the core and surface layers of $65 \AA \mathrm{C}$ to $34 \AA \mathrm{C}$. Thus, sanitary conditions did not prevail [5]. However, UV treated polyethylene covers, like poly-tunnels could be a solution [6]. The temperature profiles are similar to reported literature [6]. The particle size reductions were high in windrowing because of turnings [7]. The reduction in particle sizes increased the final bulk density by $53 \%$ in windrows as opposed to $40 \%$ in static piles. However, dry matter reductions were $13.36 \%$ and $25.10 \%$ for static piles and windrowing, respectively. The decrease of volatile solid or increase in ash content indicates that the biological constituents in MSW are reduced during the pre-treatment process.

The initial feedstock had a $\mathrm{C}: \mathrm{N}$ ratio of around 30:1 in both treatment methods and it was reduced to 18:1 after 30 days of treatment. At the beginning, emissions were unbearable in windrows but much less in static piles. The fly infestations during the first 6 days and during the presorting were enormous. But after $5^{\text {th }}$ windrowing ( 18 days) the fly infestation was not observed. The static piles were covered with flies during the entire experimentation ( 30 days). Whether windrows are small or large, the odour nuisance and cost of turning makes this method unsuitable for tropics, particularly so in the large composting plant in Colombo since piles are turned on a daily basis, somewhere within the composting plant and odour emissions as well as dust loads were intolerable [1]. In fact, the kinetic studies revealed that the maximum substrate utilization takes place after 10 days of composting and thus, mixing 10- 
day old wastes with fresh wastes increased the decomposition rate. In addition, it controlled odour as well as fly infestations.

\subsubsection{Static pipe (SP) and step grate (SG)}

The designs of SP and SG were based on large-scale applications and the SG performance was better with a volume and mass reductions of approximately $67 \%$ and $56 \%$, respectively. Higher temperatures were recorded in SG indicating better air movement through the structure, thus achieving rapid stability of wastes. The temperatures in both of the structures were maintained well above the threshold level of $55^{\circ} \mathrm{C}$ for few days. The bulk density increased from $374 \mathrm{~kg} / \mathrm{m}^{3}$ of the raw wastes to $503-538 \mathrm{~kg} / \mathrm{m}^{3}$ after 60 days of composting and the $\mathrm{C} / \mathrm{N}$ ratio was 9 . The marketable fractions of compost were $55 \%$ and the remaining, in practice to be disposed in landfills. However, some form of odour and fly control at the beginning of the composting process is a must since these were slight drawbacks in the two methods. Removal or retracting of the structure is little easier in SG as compared to SP but the cost of fabrication and maneuverability were some of the shortcomings, even in SG.

\subsubsection{Inclined step grate (ISG)}

The design of the SG was based on the ISG system. The enclosed ISG structure performed best, since considerable air movement took place even in the night because the temperature inside the reactor was higher than the cool night air temperatures, accentuating the chimney effect. When the reactor was operated during the monsoon period, the wastes were very moist, soaking wet. Thus, leachate formations were considerable. Nonetheless, leachate productions were controlled with mixing dry stabilized wastes and incoming raw wastes. The capacity too increased with increasing the recycling percentage to a maximum of $25 \%$ of payload. Further increases in capacity were obtained with the size reduction of the raw wastes. This decision was made after extensive studies on air movement through the pile. In fact at $4 \mathrm{t} / \mathrm{d}$ capacity, the air movement was so high that dehydrated the decomposing wastes far too fast. Once the size reductions were done to less than $7.5 \mathrm{~cm}$ and recycling $25 \%$, the capacity augmented to $8 \mathrm{t} / \mathrm{d}$, doubled its design specification of $4 \mathrm{t} / \mathrm{d}$. The output of the stabilized wastes was $2.5 \mathrm{t} / \mathrm{d}$ and the average bulk density was $610 \mathrm{~kg} / \mathrm{m}^{3}$.

The comparative performance was better in terms of quality, mass and volume reductions. It produced thermophillic compost that had undergone at least $75^{\circ} \mathrm{C}$ for a minimum period of one week and most of all odour and fly control problems were eliminated. The cost of operation was very low compared to any other system. Although, the initial capital costs of ISG are slightly higher compared to covered structures for windrowing, the operational costs are negligible and produced at least $60 \%$ marketable compost. However, the marketability depends on quality and quality parameter study indicated that 1:4 of compost and sand was ideal to assess germination of lettuce seeds and 60 days of stabilization and maturity is sufficient to produce good quality marketable compost [8].

\subsection{Anaerobic digestion}

\subsubsection{Vertical reactors}

The logistical growth equation could be used as a useful kinetic tool to correlate large number of parameters in laboratory scale models for optimizing hydrolytic phase anaerobic reactors. Downward movement of elutes and allowing stabilization of 7-7.5 days with subsequent feeding at 3-day intervals at maximum substrate utilization rate is optimum for continuous operations of the first phase [2]. 
In batch operations, daily as opposed to $7^{\text {th }}$ day extraction of elutes increased COD stripping and reduced the percentage of ammonia production while higher level of TKN being removed from wastes. Higher frequency of circulation increases enzyme and microbial activities. Increased flow rate may lead to less chance of short-circuiting thus providing more efficient distribution of inoculums. Higher circulation rate also improves the reactor with fresh inoculation, allowing it to reach balanced condition more quickly. This finding is in line with the observation of a study which reported that higher leachate recirculation rate; stable digester performance with increased biogas yields can be obtained [9]. Whenever it was required, the $\mathrm{pH}$ of the reactors was adjusted using $\mathrm{NaOH}$ solution to help enhance for the onset of methane phase as the $\mathrm{pH}$ range for methanogenesis is 6.5-7.3 [10].

These findings are useful in developing the required bioreactors. However, optimizing placement densities is important since at high densities, diffusion of enzymes is curtailed [2]. It is likely that there are interactive relationships between different densities that could be predicted accurately since all of the indicative parameters measured show logistical growth curves that could be predicted accurately. These relationships would indicate optimum densities that are suitable for commercial applications and would provide the basis of a scientific explanation for differences in performance between slurry and solid phase reactions [2].

\subsubsection{Horizontal reactor}

In the horizontal reactor, the $\mathrm{pH}$ values of elute varied with the phase of bacterial reactions and perhaps remained in the optimum range for acidogenesis. This may not be ideal since there was an increase in solids settlement while there was a gradual reduction in VS although TS and TDS have increased steadily. It signifies that the feeding load of the reactor could be increased. This would also lead to an increase in nitrogen levels as well as carbon content in elute. Thus, the $\mathrm{pH}$ would also reduce favouring fermentation reactions. Initially in the hydrolytic phase, the accumulation of settling solids fraction increased in a manner that a prediction can be made to follow the logistical growth equation. Thereafter, the reactor reached steady state and towards the latter part of the experimentation there was an increase in solid settlement. This increase was perhaps due to prolonging of some of the biomass remaining in the reactor, because of poor removal efficiency. Thus, the Mass Retention Time (MRT) was too long for some of the particles. In order to overcome this limitation, it is best that a new sludge (fibre) removal mechanism is developed and incorporated so as to operate the horizontal reactor continuously [2]. Most of the problems of vertical and horizontal reactors were overcome with the inclined unit that was developed at AIT.

\subsubsection{Hybrid reactor}

It was operated under both batch and continuous. The continuous feeding was applied in draw-feed mode and two different MRTs of 25 and 20 days with the loading rate of 2 and 2.5 $\mathrm{kgVS} / \mathrm{m}^{3}$ were experimented. The $\mathrm{pH}$ and alkalinity significantly decreased from day 54 to 71 (Figure 4). Therefore, the reactor was kept unfed and observed until a balanced condition was reached as indicated by the $\mathrm{pH}$ and alkalinity of the system. During the unfed period, the $\mathrm{pH}$ and alkalinity gradually increased. Similarly, increase in concentration of the methe in the biogas was also observed (Figure 5). The specific methane yields obtained were 140.35 and $62.55 \mathrm{~L} \mathrm{CH}_{4} / \mathrm{kg} \mathrm{VS}$ for loading rate 1 and 2, respectively. The highest VS degradation of $51 \%$, with biogas production rate of $401 \mathrm{~L} / \mathrm{kg} \mathrm{VS}_{\text {removed }}$ was achieved with a retention time of 25 days. However, the methane content of the biogas produced was in the range of $30-40 \%$. 
The drop of methane concentration was traced from the technical problems on reactor configuration and not on the process. The research is till in progress to overcome this problem.

\subsection{Kinetics of aerobic and anaerobic systems}

The logistic growth curves illustrate several phases of successive degradations, perhaps commencing with hydrolysis, see Figure 6. Also a single growth curve can be fitted as shown in Figure 6. The maximum transformation rate, $T r$ occur at 9.5 days. Thus mixing raw wastes with wastes that had undergone stabilization for 10 days, which were at the maximum substrate utilization rate, reduced the period of stabilization to less than 20 days from 28 days and in addition, odour and fly control was achieved.

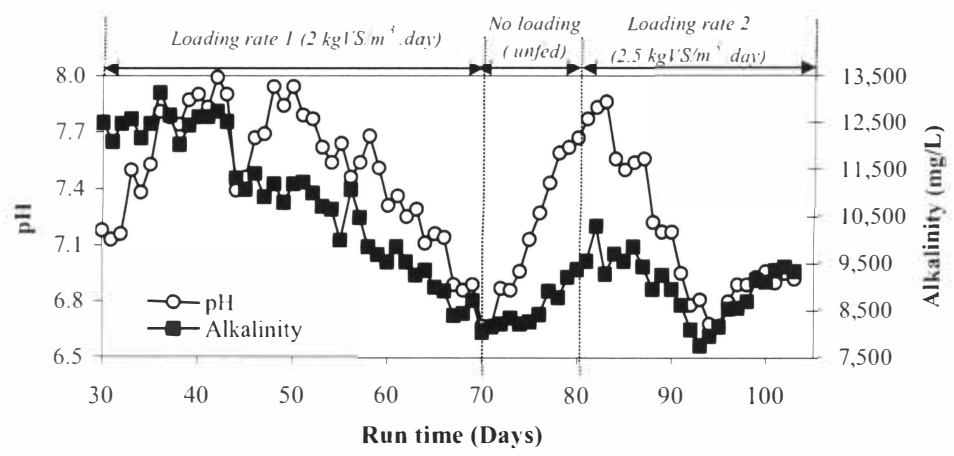

Figure 4. pH and alkalinity (Phase 2).

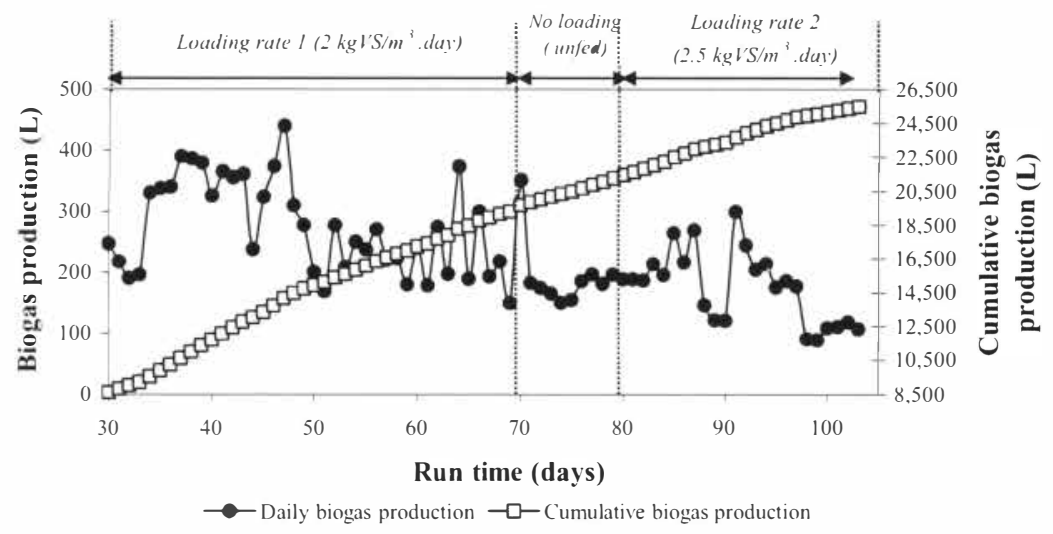

Figure 5. Biogas production (Phase 2). 
A similar pattern of decomposition phases can be identified in anaerobic digestion and an example of which is given in Figure 7. The first order equation described in many of the texts and research findings $[11,12,13]$ does not fit so well as the logistic growth equation. Also further investigations revealed that Michaelis and Menton kinetics can be applied to predict accurately the reactions of VS and VSS as substrate and microbial populations, respectively and to improve the performances of reactors [14].

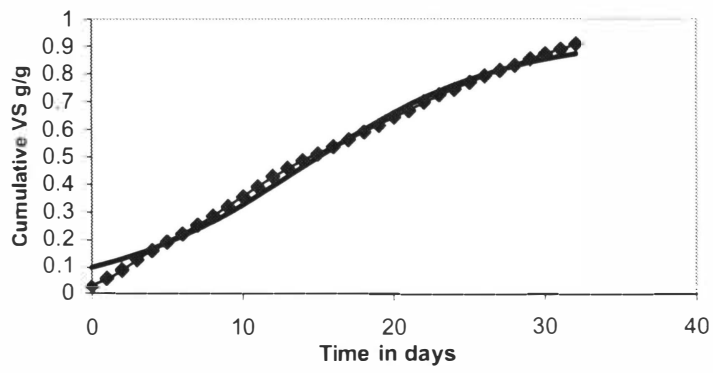

- Experimental

- Predicted with three cycles

Predicted with one cycle

Figure 6. Cumulative Volatile Solids (VS) with time for experimental and predicted curves for single and three phases of microbial growth cycles.

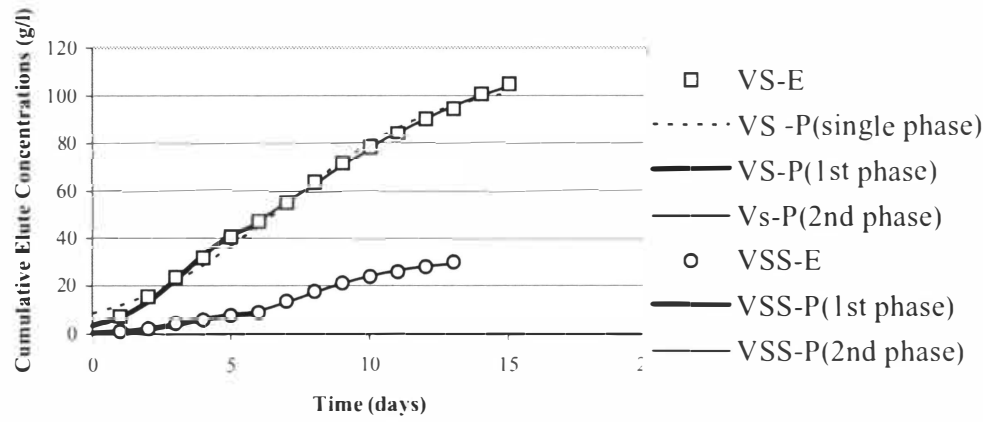

Figure 7. Logistical growth curves of single and two phases fitted for volatile solids (VS) and two phases for volatile suspended solids (VSS) of elutes from horizontal reactor at Peradeniya (E-experimental and P-Predicted).

\section{CONCLUSIONS}

It is not advisable to compost wastes in small windrows and static piles. It is best to have large ones with frequent turnings for windrows. Static piles should be aerated to ensure aerobic conditions. For any composting system to be successful, shelter is required, particularly in wet tropical locations. Mixing of ten days old stabilizing wastes with the fresh ones, is the best solution to obtain quality compost and better working conditions. All of the 
ideal conditions were maintained in the ISG reactor and it produced quality compost for agriculture use.

As applicable to aerobic systems, microbial growth kinetics enabled to optimize both vertical and horizontal reactors. The kinetic studies indicate that loading of reactor every three days was better than daily and it was achieved with the initial stabilization of 7 days without subsequent feeding. However, the horizontal hydrolytic/acidogenic reactor can be improved by increasing the pay load and improving the removal efficiency of remaining fibrous materials. The hybrid system seems to be more promising and better results are expected shortly for large scale applications.

\section{ACKNOWLEDGEMENTS}

The authors are most grateful to the Swedish International Development Cooperation Agency (SIDA) and Asian Institute of Technology (AIT) for technical and financial supports given for the project: Sustainable Solid Waste Landfill Management in Asia. The authors greatly appreciate all resource personnel of AIT-Sida project.

\section{REFERENCES}

[1] Basnayake, B.F.A., Ekanayake K.M., 2005. Evaluation of different MSW landfill pretreatment (composting) systems in Sri Lanka. Tenth International Waste Management and Landfill Symposium, Sardinia, Italy.

[2] Basnayake, B.F.A., Visvanathan, C., Wimalaweera, R.M., Mannapperuma, N.R.C., 2006. Microbial reaction kinetics for correlating first phase anaerobic reactions in laboratory and pilot scale digesters. Asian Journal of Microbiology, Biotechnology and Environmental Sciences, 8 (3), 405-411.

[3] Basnayake, B.F.A., Karunarathna, A.K., 2004. A comparative study of windrow and static pile MSW composting methods in Sri Lanka. The Journal of the Agricultural Engineering Society Sri Lanka, 8, 9-23.

[4] Menikpura, S.N.M., Basnayake, B.F.A., Boyagoda, P.B. and Kularathne, I.W. 2007. Application of waste to energy concept based on experimental and model predictions of calorific values for enhancing the environment of Kandy City. Accepted for publication. Tropical Agriculture Research Volume 19.

[5] ORCA, (1992) A review of compost standards in Europe. ORCA Technical Publication No. 2 Organic Reclamation and Composting Association, Brussels.

[6] Stentiford, E.I., Pereira, J.T., Mara, D.D., 1993. Low cost composting, research monographs No-04. Tropical Public Health Engineering, USA.

[7] Gray, K.R., Biddlestone, A.J., 1974. Decomposition of urban waste. In Biology of Plant Litter Decomposition, Vol. 02, C.H. Dickinson \& G.J.E. Pugh. (Eds), Academic Press London, London, pp 775.

[8] Pathirage, S.K., 2002. Quality parameters of compost made from MSW in the inclined step grate (ISG) unit, particular reference to particle size distribution. Thesis submitted for the Basic Degree in Agriculture, University of Peradeniya.

[9] Chugh, S., Clarke, W., Pullammanappallil, P., Rudolph, V., 1998. Effect of recirculated leachate volume on MSW degradation, Waste Management and Research, 16, (6), 564573.

[10] Gerardi, M. (2003). The microbiology of anaerobic digesters. Jonh Wiley and Sons, Inc. 
New Jersey. ISBN: 0-47\$-20693-8.

[11] Gujer W, Zhender AJB (1983) Conversion processes in anaerobic digestion. Wat. Sci. Tech.15, 127-167.

[12] Pavlostathis, S. G. and Giraldo-Gomez, E. (1991). Kinetics of anaerobic treatment. Wat. Sci. Tech. 24 (8), 35-59.

[13] Shimizu, T., Kudo, K. and Yoshikazu, N. (1993). Anaerobic waste-activated sludge digestion -a bioconversion mechanism and kinetic model. Biotechnology and Bioengineering. 41, 1082-1091.

[14] Manikpura, S.N.M., Basnayake, B.F.A., Jayakody, K.P.K., Chandrasena, A.S.H., 2007. Development of a protocol for organic waste characterization of MSW. XI International Waste Management and Landfill Symposium, Sardinia, Italy. 